\title{
Variability in historical emissions trends suggests a need for a wide range of global scenarios and regional analyses
}

\author{
Jiesper Strandsbjerg Tristan Pedersen (10 1,2凶, Detlef P. van Vuuren (10 ${ }^{3}$, \\ Bruno A. Aparício (1) ${ }^{1}$, Rob Swart ${ }^{4}$, Joyeeta Gupta ${ }^{5}$ \& Filipe Duarte Santos ${ }^{1}$
}

Long-term developments in carbon dioxide emissions have tracked the middle of projected emission scenario ranges over the past three decades. If this tendency continues, it seems increasingly less likely that future emissions will follow current high-emission scenarios. However, in the past, periods of slow and fast global emissions growth was observed, which have led to previous critiques of scenarios being too low or too high. In the light of such unpredictability and since scenarios are meant to explore plausible futures, we here argue that a broad range of emission scenarios continue to be considered input in scenario-based analyses of future climate change. Furthermore, we find substantial regional differences in emissions trends. Territorial emissions in OECD countries fall on the low side of emission scenario ranges, whereas non-OECD territorial emissions fell closer to the medium or highend. Since non-OECD emissions will become increasingly important, we recommend further exploring the relationships between regional and global emissions to support scenario assumptions and climate policymaking.

C limate change extends into the distant future ${ }^{1,2}$. Thus, in climate change research, emission scenarios play a crucial role, given the importance of evaluating the long-term consequences of near-term decisions and exploring plausible emission trajectories ${ }^{3,4}$. These emission scenarios are used as input for scenario-based literature assessing plausible future climatic changes, risks, and responses to inform policy decisions ${ }^{3}$.

Recently, the relevance of the high-emission scenario RCP8.5 of the Representative Concentration Pathways (RCP) was questioned concerning its role in the analyses of present and future emissions and climate change as it supposedly reflects very high emissions given current information $^{5-7}$. We find it essential to evaluate the subsequent scenario series used in climate change research (since the 1990s) to understand their evolution and current emissions developments to

\footnotetext{
${ }^{1}$ Climate Change Impacts, Adaptation and Modelling (CCIAM), Centre for Ecology, Evolution and Environmental Changes (cE3c), Faculdade de Ciências da Universidade de Lisboa, Campo Grande 016, C1, 2.22, 1749-016 Lisbon, Portugal. ${ }^{2}$ Social Science Institute (ICS) of the University of Lisbon, Av. Professor Aníbal de Bettencourt 9, 1600-189 Lisbon, Portugal. ${ }^{3}$ PBL Netherlands Environmental Assessment Agency, Climate, energy and air pollution, Bezuidenhoutseweg 30, 2594 AV Den Hague, The Netherlands. ${ }^{4}$ Wageningen Environmental Research, Wageningen University \& Research Corporate headquarters, Droevendaalsesteeg 4, 6708 PB Wageningen, The Netherlands. ${ }^{5}$ Governance and Inclusive Development; Geography, Planning and International Development Studies; AISSR, University of Amsterdam Nieuwe Achtergracht 166, 15629 Amsterdam, The Netherlands.

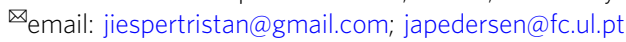


provide policymakers with relevant and valid scientific evidence and ensure that valuable information is not excluded.

The emission scenarios aim to explore possible trajectories, including those consistent with current expectations of the most likely trend and more uncertain developments. The latter include both low emission scenarios that could lead to specific climate policy goals and high scenarios that explore the upper range of possible futures and high impacts ${ }^{3,8,9}$. It is important to regularly reassess these emission scenarios in light of changing circumstances $4,10,11$. The (policy) relevance of specific emission scenarios has often been debated ${ }^{11,12}$ : for instance, the assumptions of low-end emission scenarios have been questioned as not being feasible ${ }^{12,13}$, while high-emission scenarios were questioned as being too low ${ }^{11,14,15}$. The latter assessments were formulated during periods of rapid economic and emission growth that have regularly occurred over the current and previous centuries ${ }^{16,17}$. Thus, history shows that it is difficult to assess long-term trends based on just a few years of data ${ }^{4,18}$.

Overall, over the last 30 years emissions have fluctuated around the middle of the scenario range-as possibly intended-but also making current high-emission scenarios less likely. Simultaneously, history has also shown high variabilities in growth rates and future departures from long-term trends cannot be excluded. These findings emphasize that it is problematic to operate with best-guess scenarios only since they have historically had short shelf lives. Therefore, it is still relevant to base future climate projections on a wide range of emission scenarios. Moreover, future studies that explore regional relationships in emissions developments are needed and recommended for policymaking.

\section{Historically, global emissions have tracked the middle-of-the- scenario ranges}

Here, we focus on the emission scenarios used in scenario-based literature informing the Intergovernmental Panel on Climate Change's (IPCC) assessment reports ${ }^{3}$. We compare the emission scenarios with recent trends in carbon dioxide (CO2) emissions from fossil-fuel combustion, cement production, and gas flaring ${ }^{16}$. $\mathrm{CO}_{2}$ emissions are the most significant contributor to longterm climate change ${ }^{2}$ and thus provide a good reference to regularly assess the implications of developments of emissions and their socioeconomic drivers with the emission scenarios ${ }^{11,16}$ used as the basis for science and policy assessments. The IPCC process has resulted in four generations of emission scenarios ${ }^{3}$. Three were developed under the mandate of the IPCC: Scientific Assessment 1990 (SA90) ${ }^{19}, 1992$ IPCC Scenarios (IS92) ${ }^{20}$, and the Special Report on Emission scenarios (SRES) ${ }^{21}$. The fourth comprises the Representative Concentration Pathways (RCPs) ${ }^{9}$ and Shared Socioeconomic Pathways (SSPs) ${ }^{8}$, which informed Phase 5 and 6 of the Climate Model Intercomparison Project $\left(\right.$ CMIP5/CMIP6) ${ }^{22}$. The RCPs have been used in scenario-based literature informing the IPCC Fifth Assessment Report (AR5), while the SSP/RCP combination will be used for the IPCC Sixth Assessment Report (AR6). CMIP6 made a selection of the SSP/ RCP combinations ${ }^{22}$ that will be highlighted in AR6. These are therefore shown separately, labeled as SSP CMIP6, in the figures.

Comparing the global average emissions growth rate in these scenarios with historical emissions shows that historical emissions roughly fall around the middle-of-the-scenario ranges (Fig. 1).

The historical global emissions are roughly aligned with SA90A, IS92a, RCP4.5, SSP2 and SSP1-2.6, and SSP4-3.4/6.0 (CMIP6) (Fig. 1). Overall, the scenario range forms an almost symmetrical bracket around the historical emission trend for each scenario exercise. It should be noted that the IS92, SRES, SSP-baselines, and several RCPs do not include new climate policies-and thus they represent possible reference cases to assess policies.
Global $\mathrm{CO}_{2}$ emissions have increased by $40 \%$ (from $6.2 \mathrm{GtC}$ in 1990 to $10 \mathrm{GtC}$ in 2018), with an average annual growth rate of $1.7 \%$. The period covers three sub-periods of overall medium-low growth (1992-1998: 0.6\%), high growth (1999-2012: 2.6\%), and overall medium-low growth (2013-2018: 0.8\%). In 2019, emission growth was relatively low $(0.6 \%)^{16}$, and a temporary drop (between -3 and $-7 \%$ ) is expected for 2020 due to the Covid-19 pandemic's effect on economic activities ${ }^{23,24}$.

Since 2000, the most recent historical high-growth period began just after the SRES publication. Several publications noted that emissions were tracking the high-end emission scenarios ${ }^{11,14,15}$. However, we find that on average, emission growth over the last three decades has fallen between the medium and high-emission scenarios. The high growth period ended around the SSP publication, explaining the significantly lower historical growth rate averages assumed in the SSPs. As a result, the historical trend is at the low end of the SSP baseline range. This slow growth may be attributed to a combination of slow historical global economic growth rates ${ }^{17}$ (which were also below the SSP baseline range $e^{8}$ ), rapid technological development of some renewable resources ${ }^{25,26}$ (partly a result of policies), increasing natural gas use (driven by new production routes ${ }^{27}$ ), and climate policy implementation ${ }^{28,29}$.

In essence, the long-term historical developments ( 20-30 years) suggest that the world has followed an emission pathway in the middle of IS92, SRES, RCP, and SSP scenario ranges. Simultaneously, shorter-term trends show high variability, emphasizing the importance of maintaining a broad emission range for future emission scenarios.

\section{Implications for defining BAU or best-guess scenarios}

Over the historical period, emissions have thus tracked the middle of emission scenario ranges, slowly moving to a slowgrowth period in the last few years. It seems logical to conclude that it is more likely than eight years ago ${ }^{11}$ that emissions (and global warming) will follow a trajectory much lower than RCP8.56. Together with RCP4.5 and RCP6.0, RCP8.5 was initially published as one of a set of three possible baseline scenarios, describing a low-end, median, and high-end baseline trends (in the absence of climate policy), respectively. It was stated that it was, at the high-end, close to the 90th percentile of emission scenarios published at that time ${ }^{9}$.

However, some researchers in the community that uses emission scenarios as input quickly picked up RCP8.5 as a business-as-usual scenario (BAU). In the primary literature, the BAU term was only used in the SA90 series for a scenario without policy assumptions $(\text { SA90-A })^{19}$. Historically, the BAU concept and policy assumptions were excluded from scenario developments by the IPCC terms of reference in $1991^{30,31}$. After this, the developers have created scenarios with similar assumptions as SA90-A. Such scenarios have been described as continued historical trends (IS92a) ${ }^{20}$, dynamicsas-usual (SRES-B2) ${ }^{8}$, or middle-of-the-road (SSP2) ${ }^{8}$. These were not intended as a best-guess or BAU scenario.

A BAU choice or a best-guess scenario is complicated and subjective since it reflects assumptions that may change from decade to decade as new societal trends make in-roads and plausibly affect emissions trends. The high focus on RCP8.5 from the scientific community ${ }^{5}$ may have been a consequence of the 1999-2012 high-emission period ${ }^{16}$ and the scenario-assessments discussing a plausible too low emission range ${ }^{11,14,15}$. The appraisal that RCP8.5 should not be described as 'the' BAU scenario $^{5,6}$ is thus entirely in line with its initial intention as a relatively unlikely, but still plausible high-emission case ${ }^{9}$.

Politicians or policymakers do not always consider uncertainty ranges $^{32}$ and sometimes request best-guess estimates from researchers. However, historically best-guess scenarios have had 


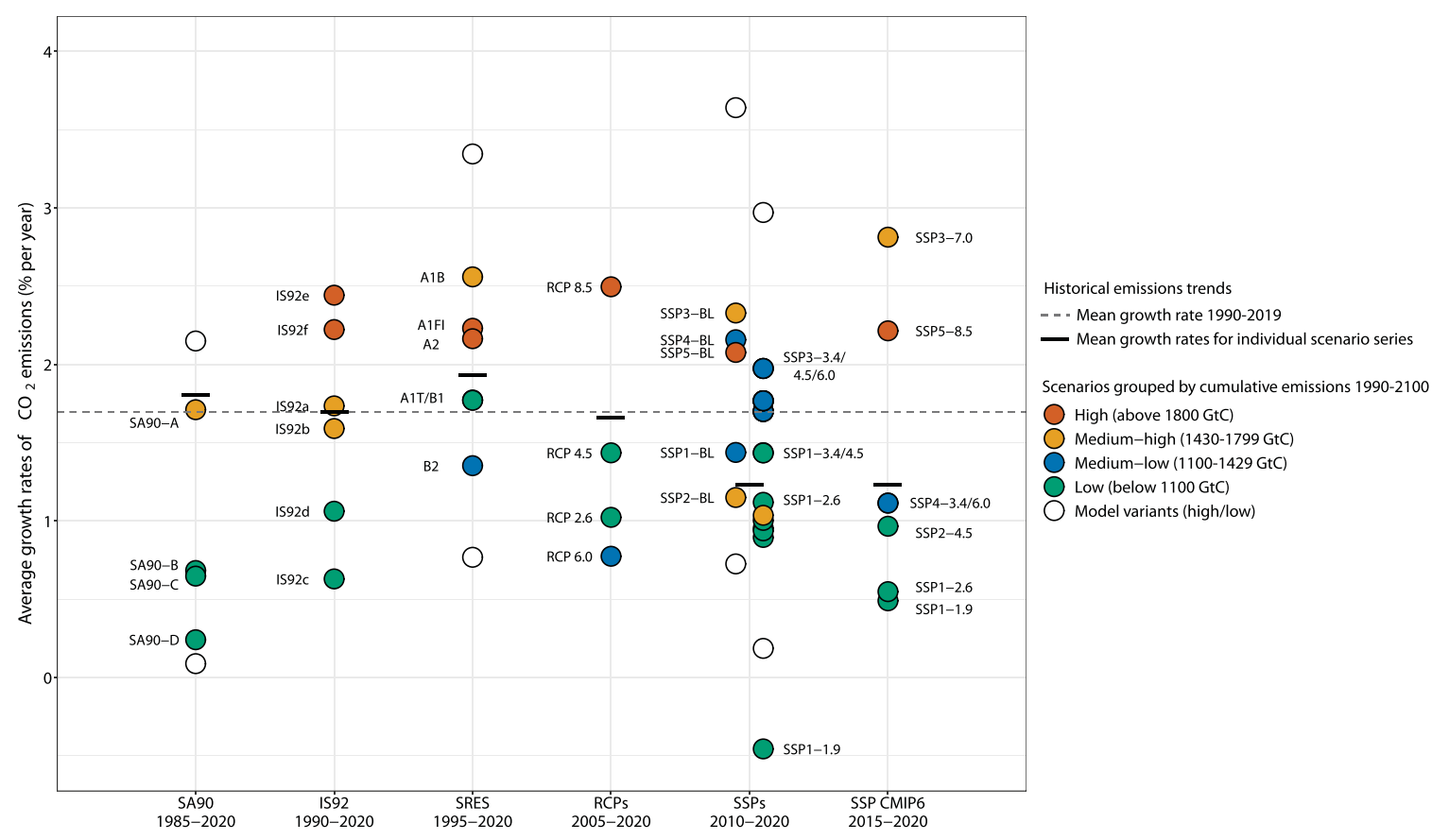

Fig. 1 Global growth rates of historical and scenario $\mathbf{C O}_{\mathbf{2}}$ emissions from fossil fuels and industry. The average scenario growth rates of emissions are calculated for individual marker/illustrative scenarios (filled circles) and low/high model variants (open circles) covering the actual projected period for each series ${ }^{8,9,19-21}$ compared to growth rates of historical emissions ${ }^{16}$ for the equivalent periods (short black lines) and the IPCC period $1990-2019$ (dashed gray horizontal line). Individual growth rate lines (short black lines) cover SA90 (34 years), IS92 (29 years), SRES (24 years), RCPs (14 years), SSP-baselines (left) \& SSP-mitigation (right) (9 years), and SSP CMIP6 (4 years) ${ }^{8,22}$. Scenarios are grouped into four cumulative emissions categories (Total $\mathrm{CO}_{2}$ emissions 1990-2100) ${ }^{55}$ : low (bluish-green), medium-low (Blue), medium-high (orange), and high (vermillion) emissions-the color-coding is optimized for readers with color blindness ${ }^{56}$. For some of the scenarios, the growth rates (1985-2020) do not necessarily reflect the century-long emission trajectory of the scenarios (e.g., several scenarios have a peak-and-decline shaped trajectory, such as SA90-B, IS92C, SRES-A1B/T/B1, RCP4.5, SSP1, and SSP4). The scenario databases commonly report emissions at intervals of 5, 10, or 25 years. The Compound Annual Growth Rates (CAGR) method was used since it calculates the beginning and end value, providing a consistent growth rate comparison between projections and historical developments. Projected scenario estimates for the years 1990, 2020 (SA90), and 1995 (SRES) were calculated using linear interpolation, which is considered robust ${ }^{11}$. (See Supplementary Fig. 1 and Tables 1 and 2, 4-9).

limited shelf lives: Between 2007 and 2013, a best-guess scenario could have been RCP8.5 ${ }^{11,14}$, and during the $1990 \mathrm{~s}$ - before the last high growth period-the IS92a (medium-high) was an often preferred reference scenario for mitigation and stabilization studies ${ }^{33,34}$. To inform decisions with a long lead time for planning and implementation, information about the full range of uncertainty is relevant $^{35,36}$ for decision-makers to be aware of uncertainties and make decisions that are robust or adaptive to such uncertainties.

In essence, best-guess scenarios may not be the best way to reduce complexity and simplify the interpretation of scenarios for policymakers. The recommendation of attaching a set of bestestimate or probabilities to future emission scenarios to assess future climate change ${ }^{6}$ may provide a false sense of certainty to decision-makers and additionally costly adjustments if the world evolves in unanticipated ways ${ }^{37}$.

\section{Implications for low- and high-end emission scenarios}

The RCP8.5 does not describe a continuation of current trends but a scenario for analyzing low-probability high-impact events. In the light of recent scientific discussions, is RCP8.5 still relevant for this purpose? By definition, if emissions track the middle-ofthe-scenario range, both the low and high-end scenarios will become less likely over time. For instance, the lower bounds of the emission scenario series during the 1990-2020 period have moved up in the successive sets from SA90 to SSPs, arguably adapting to rising historical estimates over time $e^{8,19-21}$.
A lesson from our historical analysis is that there are unpredictable changes in global economic conditions (and technological advances) that have a relatively immediate impact on emission trends. Thus, it is wise to have modest expectations when we estimate the emission range, given the reversal of different global trends at different times (as illustrated in Fig. 2a). Therefore, the key question is whether the factors that have caused the recent historical change of a high-emission growth period (1999-2012) to a medium-low growth period (2013-present) are structural and different from when they were assessed in the past. One may expect some of the factors leading to slower emission growth ${ }^{16}$ (recent medium-low energy growth $^{38}$, emerging climate policies ${ }^{28,39}$, and decreasing costs of renewables ${ }^{25,26}$ ) to be structural ${ }^{6}$. Thus, both medium-low and low emission scenarios remain plausible and should be regularly reassessed since they relate to important policy goals. But does it automatically mean that emission trends could not pick up speed again?

At odds with the results of the growth rate comparisons, according to recent research, historical cumulative emissions 2005-2020 track RCP8.5 emissions closely ${ }^{40}$. We find that total historical cumulative $\mathrm{CO}_{2}$ emissions for both the 1990-2020 period (288 GtC) and 2005-2020 (168 GtC) are close to the projections in medium-highemission scenario IS92a and SSP3-7.0, and high-emission scenarios SRES-A2, SRES-A1FI, RCP8.5, SSP5, and SSP5-8.5 (Supplementary Table 3). High-emission scenarios are still of importance to account for possible extreme outcomes. 

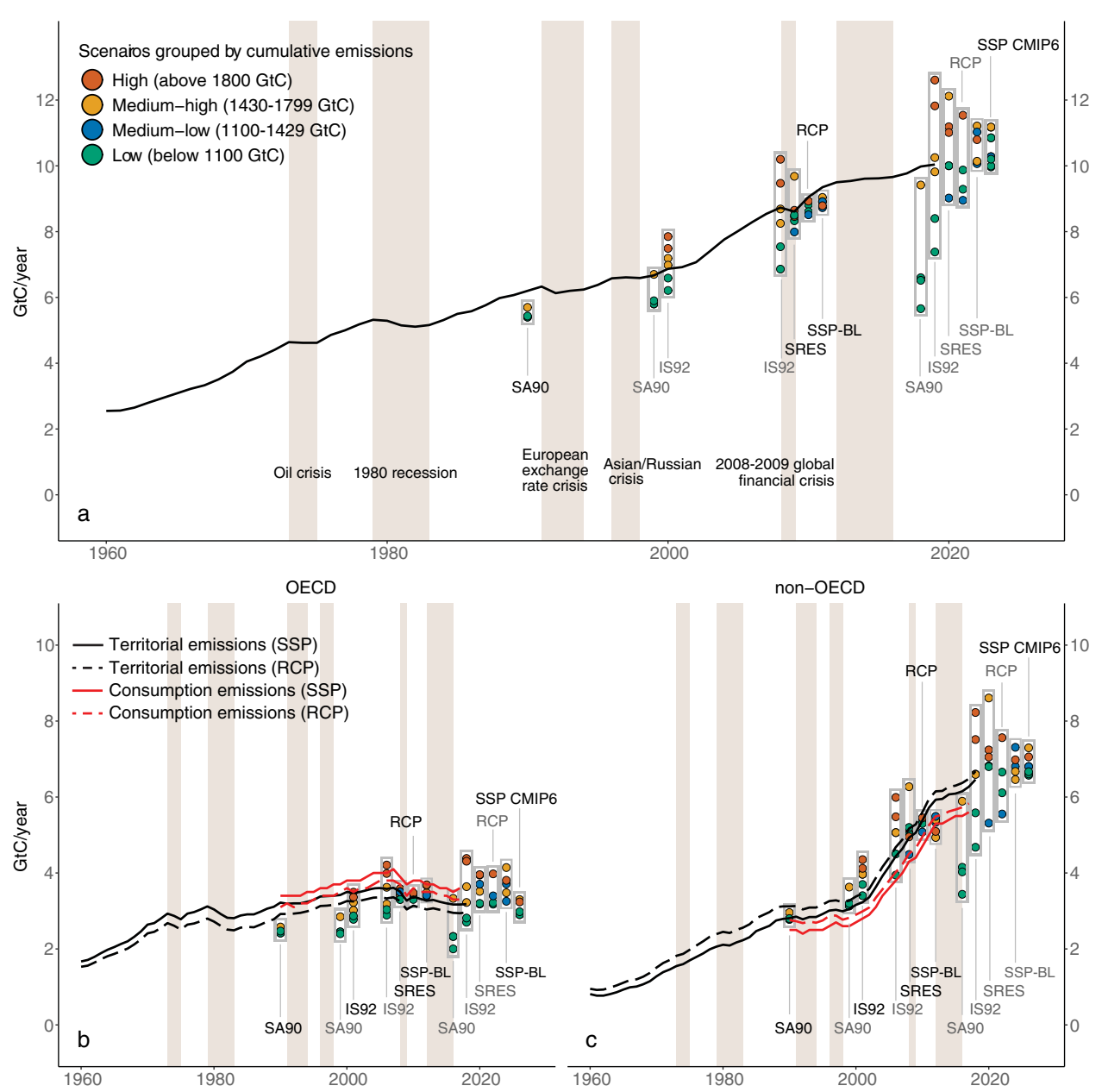

Fig. 2 Global, non-OECD, and OECD historical CO2 emissions (1959-2018) compared to SA90, IS92, SRES, RCP, SSP-BL, and SSP (CMIP6) emission scenarios. a Global emissions with low to medium-low growth periods of $\leq 1 \%$ annual growth (gray shaded areas) and periods of global emissions growth above $1 \%$ (white areas). b OECD territorial/production (black) and consumption (red) emissions ${ }^{16}$ compared to scenario projections. c non-OECD territorial/production (black) and consumption emissions (red) compared to scenario projections. Historical data are presented by solid lines (SSP definitions ${ }^{8}$ ) and dashed lines (RCP definitions ${ }^{9}$ ). The definitions of OECD and non-OECD differ between the SA90 ${ }^{19}$, IS92 ${ }^{20}$, SRES $^{21}$, RCP $^{2}$ and SSP databases (e.g., RCP OECD is based on OECD90 (32 countries) and thus including fewer countries than the SSP OECD category, including OECD90 + EU member states and candidates (44)). Scenarios are grouped into four cumulative emissions categories (total $\mathrm{CO}_{2}$ emissions 1990-2100): low (bluishgreen), medium-low (Blue), medium-high (orange), and high (vermillion) emissions. (Furthermore, see growth rate comparisons in Supplementary Fig. 2).

There are several possible ways in which the future can unfold. Governments in various countries could actively continue using fossil fuel, regardless of the Paris Agreement's international ambitions. Some political leaders in key countries (e.g., the United States and Brazil) support $\mathrm{CO}_{2}$ intensive economic growth, while fossil fuels are still heavily subsidized in EU member states ${ }^{41}$, despite climate policies. Digitalization could lead to increased efficiency ${ }^{42}$, but could also increase energy use via new energyrequiring activities. The energy poverty and availability of fossilfuel resources in low-income countries could increase fossil rather than renewable energy investments, supported by investments from high-income countries ${ }^{43,44}$. New developments in energy extraction in the African ${ }^{45}$ and Polar regions could lead to a drop in fossil-fuel extraction costs and enhanced energy-intensive economic growth. Also, the global population's persistent growth together with increasing per capita consumption and energy use play an important role, albeit from a low base in economies that have currently low incomes and historically low emissions. Population growth could track the UN high scenario (15.5 billion by 2100$)^{46}$ instead of 12 billion in RCP8.59, and economic growth could be underestimated in the RCPs/SSPs ${ }^{47}$.
Moreover, it is difficult to foresee the aftermath of the Covid-19 pandemic. There has been a clear drop in energy use and strong voices arguing for green recovery packages. However, low fossilfuel prices may reduce renewable energy investments seeing fast economic recovery without sustainability conditions, which may slow down climate policy ${ }^{7}$. Finally, recent insights into climategreenhouse gas feedbacks suggest that earth-system emissions in response to climate change could be higher than those currently included in the models ${ }^{48}$.

Given these plausible future developments, both low and highemission scenarios are still possible. To provide support for meaningful decision-making, via scenario-based literature, also the outer ends of the plausible emission scenario range with associated low and high climate impacts remain relevant to inform mitigation and adaptation challenges.

\section{Global emission trends hide very different regional dynamics and key linkages}

To better understand possible future global emissions, it is crucial to consider regional emissions and their drivers. The historical global average hides underlying regional trends, making it 
important to look at regional emission trends such as those from OECD and non-OECD regions. Assessing the slow growth periods, global emission growth (Fig. 2a: vertical gray shaded areas) was determined mainly by OECD member countries during the 1970s and 1980s (Fig. 2b, c). In comparison, the slow growth during the 1990s characterized both OECD and non-OECD trends. During the last slow growth period, both global and nonOECD emissions' slope broke to a less steep curve simultaneously from 2013 onwards, while the OECD emissions stabilized or decreased a couple of years earlier (from 2010).

Since 1990, emission growth has been dominated by countries with no emissions limitation targets ${ }^{49}$ and low per capita emissions ${ }^{15,49,50}$, and by the USA and Canada, which did not ratify the Kyoto Protocol, with resulting increase in emissions till $2008^{16}$. As such, it is relevant to consider if regional emissions have grown faster or slower than projected and if new assumptions may strengthen future projections. While the historical trend is closer to the medium-low and low-end of the scenario range in OECD countries, it is closer to the medium-high and high-end of the scenario range in non-OECD countries (Fig. 2b, c).

These observations mainly tell us something relative: that non-OECD scenarios may have been a bit too low and OECD scenarios too high compared to reality (territorial emissions). And thus, non-OECD is getting more important in the future. The recent trend in OECD countries is partly caused by increasing renewable investments ${ }^{38}$, increased energy efficiency, and climate policy ${ }^{28}$, but also by the trend of exporting (mostly fossil-fuel related) energy investments ${ }^{43}$ and industrial production to non-OECD regions ${ }^{51}$. Accounting for the industrial energyexport ${ }^{16}$, OECD consumption-related emissions tracked mediumhigh and high-emission scenarios closely. While some of the factors such as policy and energy efficiency also play a role in nonOECD countries, they have not led to a downward shift in emission trends.

Historically, the more prosperous countries were expected to reduce their emissions to allow for fossil driven developments in low-income countries, under climate change regime ${ }^{49}$. Additionally, a bulk of the remaining global fossil-fuel reserves are located in the global south, which has attracted exploitive energy corporations based in high-income countries such as the United States, Asian, and climate policy leading EU member states $43,45,52$. If such authoritative trends continue, this may support continued global inequality, e.g., as described in the SSP3 and SSP4 storylines. SSP4 represents high adaptation challenges in low-income countries, and SSP3 high mitigation and adaptation challenges.

One may note that emissions from non-OECD countries could represent a key to future emissions developments. In particular, since the non-OECD group contains a larger number of countries, people and landmass compared to the OECD group and are on an earlier stage of economic development, their future development may lead to greater energy use.

Retrospectively, the SA90 and IS92 scenarios had low growth rates for developing countries ${ }^{50}$, compared to the global convergence scenarios of the SRES (and SSP) series. Continued fossil investments in low-income countries ${ }^{43}$ may cause stranded assets $^{53,54}$ but also long-term structural inertia. Hence, a substantial driver of growing energy demand in the future may be continuing economic convergence between the global North and South-with rapid economic growth in large economies like India and China. To curb global emissions, it appears crucial to analyze national responsibilities both within and outside national borders. As such, consumption and energy investments represent two areas of plausible interest for policymaking and UNFCCC negotiations.

\section{Conclusion and future outlooks}

We conclude that it is still realistic to assume that global emissions can track high-emission scenarios. One may argue that although fast emission growth has become undoubtedly less likely, high-end scenarios such as RCP8.5 are not yet impossible and still relevant. In particular, to assess the full range of possible climate change impacts for investments with long time horizons. Therefore, the full range of emission scenarios remains important as inputs to scenario-based analysis assessing possible climate impacts, particularly for investments with long time horizons. But for this, RCP8.5 should be described as a low-possibility, highimpact case, and not as a business-as-usual case. Best-guess scenarios tend to have a short shelf life and using only those may lead to a mistaken sense of certainty for scenario-based assessments and policy decisions. Medium scenarios may represent best-guesses, and thus IS92a may present an example of a bestguess scenario that has matched the historical global emissions pathway well. However, IS92a has been less successful in capturing historical developments in regional emissions.

Regarding mitigation analyses, the choice of a high or medium baseline is less relevant since, especially in the short-term, the gap between any baseline scenario and $2^{\circ}$ or $1.5^{\circ}$ scenarios is still very large, requiring global emissions to be urgently reduced.

The essence of emission scenario development is to explore a range of possible pathways and their relevance. The long history of inaccurate predictions concerning oil prices or energy use demonstrates that it has been, and it will remain challenging to foresee shifts in economic and technological development paths at the global and regional levels. Hence, providing a wide range of scenarios with distinct regional characteristics remains a fundamental approach to inform policy meaningfully. If high-emission scenarios would ever be realized, this may particularly result from developments in non-OECD emissions as they are linked to consumption in the OECD countries, the still large quantities of fossil-fuel reserves available in the South, and associated national and international energy investments. Even if territorial emissions in OECD countries would decrease, the implications of economic interconnections between high- and low-income countries for global emissions should be further investigated, e.g., in new scenario analysis.

\section{Data availability}

The data sets generated during and/or analyzed during the current study are available from the corresponding author on reasonable request. The majority of data generated or analyzed during this study are included in this published article (and its supplementary information files).

Received: 30 June 2020; Accepted: 5 October 2020; Published online: 30 October 2020

\section{References}

1. Raskin, P., Monks, F., Ribeiro, T., van Vuuren, D. \& Zurek, M. Global Scenarios in Historical Perspective. Ecosystems and Human Well-Being: Scenarios: Findings of the Scenarios Working Group 35-44. https://pdfs. semanticscholar.org/780d/43ae4d93304b3d4d31f229656fd1d2aa02d5.pdf (2005).

2. Intergovernmental Panel on Climate Change. Climate Change 2014 Synthesis Report (2014).

3. Moss, R. H. et al. The next generation of scenarios for climate change research and assessment. Nature 463, 747-756 (2010).

4. van Vuuren, D. P. et al. What do near-term observations tell us about longterm developments in greenhouse gas emissions? Clim. Change 103, 635-642 (2010)

5. Pielke, R. \& Ritchie, J. Systemic misuse of scenarios in climate research and assessment. SSRN Electr. J. https://doi.org/10.2139/ssrn.3581777 (2020).

6. Hausfather, Z. \& Peters, G. P. Emissions - the 'business as usual' story is misleading. Nature 577, 618-620 (2020). 
7. Tollefson, J. How hot will Earth get by 2100? Nature 580, 443-445 (2020).

8. Riahi, K. et al. The Shared Socioeconomic Pathways and their energy, land use, and greenhouse gas emissions implications: an overview. Global Environ. Change 42, 153-168 (2017).

9. van Vuuren, D. P. et al. The representative concentration pathways: an overview. Clim. Change 109, 5-31 (2011).

10. Richels, R. G., Tol, R. S. J. \& Yohe, G. W. Future scenarios for emissions need continual adjustment. Nature 453, 155-155 (2008).

11. Peters, G. P. et al. The challenge to keep global warming below $2{ }^{\circ} \mathrm{C}$. Nat. Clim. Change 3, 4-6 (2013).

12. Pielke, R., Wigley, T. \& Green, C. Dangerous assumptions. Nature 452, 531-532 (2008).

13. Fuss, S. et al. Betting on negative emissions. Nat. Clim. Change 4, 850-853 (2014).

14. Raupach, M. R. et al. Global and regional drivers of accelerating $\mathrm{CO} 2$ emissions. Proc. Natl Acad. Sci. USA 104, 10288-10293 (2007).

15. Le Quéré, C. et al. Trends in the sources and sinks of carbon dioxide. Nat. Geosci. 2, 831-836 (2009).

16. Global Carbon Project. Supplemental data of global carbon budget 2019 (Version 1.0) [Data set]. https://doi.org/10.18160/gcp-2019 (2019)

17. World Bank. GDP, PPP (constant 2011 international \$). The World Bank Data. https://data.worldbank.org/indicator/NY.GDP.MKTP.PP.KD (2019).

18. Manning, M. R. et al. Misrepresentation of the IPCC $\mathrm{CO} 2$ emission scenarios. Nat. Geosci. 3, 376-377 (2010).

19. Intergovernmental Panel on Climate Change. Climate Change: The IPCC Response Strategies, Working Group III. (1990).

20. Leggett, J. et al. Emissions scenarios for the IPCC: an update. Climate Change 1992: The Supplementary Report to the IPCC Scientific Assessment 69-95 (1992).

21. Nakicenovic, N. \& Swart, R. Special Report on Emissions Scenarios (Cambridge University Press, 2000).

22. O'Neill, B. C. et al. The Scenario Model Intercomparison Project (ScenarioMIP) for CMIP6. Geosci. Model Dev. 9, 3461-3482 (2016).

23. Le Quéré, C. et al. Temporary reduction in daily global $\mathrm{CO} 2$ emissions during the COVID-19 forced confinement. Nat. Clim. Change 1-7 https://doi.org/ 10.1038/s41558-020-0797-x (2020).

24. Liu, Z. et al. COVID-19 causes record decline in global CO2 emissions. Cornell University http://arxiv.org/abs/2004.13614 (2020).

25. IRENA. Renewable Power Generation Costs in 2018. International Renewable Energy Agency. https://www.irena.org/publications/2019/May/Renewablepower-generation-costs-in-2018 (2019).

26. Observ'ER. The State of Renewable Energies in Europe. 2018 edn. 18th EurObserv'ER Report 288. https://www.eurobserv-er.org/category/2018/ (2019).

27. Cremonese, L., Weger, L. B., Van der Gon, H. D., Bartels, M. P. \& Butler, T. Emission scenarios of a potential shale gas industry in Germany and the United Kingdom. Elem. Sci. Anth. 7, 18 (2019).

28. United Nations Environment Programme. Emissions Gap Report 2019 (2019).

29. International Energy Agency. World Energy Outlook 2019 (2019).

30. Intergovernmental Panel on Climate Change. Report of the 6th Session of the IPCC. https://www.ipcc.ch/meetings/session06/sixth-session-report.pdf (1991).

31. Pepper, W. J. et al. Emission Scenarios for the IPCC. An Update. Background Documentation on Assumptions, Methodology, and Results (IPCC, 1992).

32. Tulkens, P. \& Tulkens, H. The White House and the Kyoto Protocol: double standards on uncertainties and their consequences. SSRN Electr. J. https://doi. org/10.2139/ssrn.910811 (2011).

33. Intergovernmental Panel on Climate Change. TAR Climate Change 2001: Mitigation (2001).

34. Alcamo, J. et al. Climate Change 1994. Radiative Forcing of Climate Change and an Evaluation of the IPCC 1992 IS92 Emission Scenarios (Intergovernmental Panel on Climate Change, 1995).

35. Oppenheimer, M. et al. IPCC Special Report on the Ocean and Cryosphere in a Changing Climate (eds Pörtner, H.-O. et al.) (2019)

36. Hinkel, J. et al. Meeting user needs for sea level rise information: a decision analysis perspective. Earth's Future 7, 320-337 (2019).

37. Lawrence, J., Haasnoot, M. \& Lempert, R. Climate change: making decisions in the face of deep uncertainty. Nature 580, 456-456 (2020).

38. International Energy Agency. Total primary energy supply (TPES) by source, World 1990-2017. World Energy Balances https://www.iea.org/statistics (2019).

39. Rogelj, J. et al. Perspective: Paris agreement climate proposals need boost to keep warming well below $2^{\circ} \mathrm{C}$. Nat. Clim. Change 534, 631-639 (2016).

40. Schwalm, C. R., Glendon, S. \& Duffy, P. B. RCP8.5 tracks cumulative CO2 emissions. Proc. Natl Acad. Sci. USA 117, 202007117 (2020).

41. Coady, D., Parry, I., Sears, L. \& Shang, B. How large are global fossil fuel subsidies? World Dev. 91, 11-27 (2017).
42. Grubler, A. et al. A low energy demand scenario for meeting the $1.5^{\circ} \mathrm{C}$ target and sustainable development goals without negative emission technologies. Nat. Energy 3, 515-527 (2018).

43. Doukas, A. et al. Talk is cheap: how G20 governments are financing climate disaster. http://priceofoil.org/content/uploads/2017/07/talk_is_cheap_G20_ report_July2017.pdf (2017).

44. Rawoot, I. Gas-rich Mozambique may be headed for a disaster. Al Jazeera. https://www.aljazeera.com/indepth/opinion/gas-rich-mozambique-headeddisaster-200223112556449.html?fbclid=IwAR24wdzuzb8WPPIXQPDDP7Rj4LBi6Q6-aNWwRGzQsbowu6yUJGz0utxtII (2020).

45. Crooks, E. Mozambique to become a gas supplier to world. Financial Times. https://www.ft.com/content/d34685b2-7995-11e8-bc55-50daf11b720d (2018).

46. United Nations Department of Economic and Social Affairs Population Division. World Population Prospects 2019 Online edn. Rev. 1. https:// population.un.org/wpp/Download/Probabilistic/Population/ (2019). Retrieved 15 April 2019.

47. Christensen, P., Gillingham, K. \& Nordhaus, W. Uncertainty in forecasts of long-run economic growth. Proc. Natl Acad. Sci. 115, 5409-5414 (2018).

48. Hausfather, Z. \& Betts, R. Analysis: how 'carbon-cycle feedbacks' could make global warming worse. Carbon Brief. https://www.carbonbrief.org/analysishow-carbon-cycle-feedbacks-could-make-global-warming-worse (2020).

49. United Nations Framework Convention on Climate Change. Kyoto Protocol to the United Nations Framework Convention on Climate Change. FCCC/CP/ 1997/L.7/Add.1. https://unfccc.int/documents/2409 (1997).

50. Parikh, J. K. IPCC strategies unfair to the South. Nature 360, 6404 (1992).

51. Peters, G. P., Davis, S. J. \& Andrew, R. A synthesis of carbon in international trade. Biogeosciences 9, 3247-3276 (2012).

52. Build, S. Avanço da exploração e produção de petróleo e gás natural em Moçambique: Contribuição das marcas que operam no país. Superbrands Moçambique http://superbrands.co.mz/o-avanco-da-exploracao-e-producaode-oleo-e-gas-natural-em-mocambique-contribuicao-das-marcas-queoperam-no-pais/ (2018)

53. Bos, K. \& Gupta, J. Stranded assets and stranded resources: Implications for climate change mitigation and global sustainable development. Energy Res. Soc. Sci. 56, 101215 (2019).

54. Mercure, J.-F. et al. Macroeconomic impact of stranded fossil fuel assets. Nat. Clim. Change 8, https://doi.org/10.1038/s41558-018-0182-1 (2018)

55. Intergovernmental Panel on Climate Change. IPCC Special Report: Emission Scenarios. Summary for Policymakers (IPCC, 2000).

56. Wong, B. Points of view: color blindness. Nat. Methods 8, 6 (2011).

\section{Acknowledgements}

Joyeeta Gupta acknowledges support from the "Netherlands Organisation for Scientific Research" (NWO) [project number W07.303.104] and the "Governance and Inclusive Development Group" of the University of Amsterdam in conducting this research. Jiesper Pedersen acknowledges support from "ANTHS - Innovation Anthropology" (Denmark) and the research unit "CCIAM-cE3c", University of Lisbon (Portugal).

\section{Author contributions}

All authors contributed to the planning of the paper. J.S.T.P. and D.P.v.V. led the work B.A.A. and J.S.T.P. prepared the figures and the associated analysis. J.S.T.P. did the mean annual growth rates, interpolations, and cumulative emissions calculations. J.S.T.P. and D.P.v.V. processed the primary structure, and writing and all authors J.S.T.P., D.P.v.V., B.A.A., R.S., J.G., and F.D.S. contributed to data interpretation, revisions, and paper writing. RS supported scenario analyzes, J.G. regional analyzes, and F.S. emissions and socioeconomic trends.

\section{Competing interests}

The authors declare no competing interests.

\section{Additional information}

Supplementary information is available for this paper at https://doi.org/10.1038/s43247 020-00045-y.

Correspondence and requests for materials should be addressed to J.S.T.P.

Peer review information Primary handling editor: Heike Langenberg.

Reprints and permission information is available at http://www.nature.com/reprints

Publisher's note Springer Nature remains neutral with regard to jurisdictional claims in published maps and institutional affiliations. 
(c) (i) Open Access This article is licensed under a Creative Commons Attribution 4.0 International License, which permits use, sharing, adaptation, distribution and reproduction in any medium or format, as long as you give appropriate credit to the original author(s) and the source, provide a link to the Creative Commons license, and indicate if changes were made. The images or other third party material in this article are included in the article's Creative Commons license, unless indicated otherwise in a credit line to the material. If material is not included in the article's Creative Commons license and your intended use is not permitted by statutory regulation or exceeds the permitted use, you will need to obtain permission directly from the copyright holder. To view a copy of this license, visit http://creativecommons.org/ licenses/by/4.0/.

(C) The Author(s) 2020, corrected publication 2020 